\title{
СОЦИОПЕДАГОГИЧЕСКАЯ МОДЕЛЬ ВЗАИМОДЕЙСТВИЯ УЧРЕЖДЕНИЙ БИБЛИОТЕЧНОГО ТИПА И ОБРАЗОВАТЕЛЬНЫХ УЧРЕЖДЕНИЙ ДОШКОЛЬНОЙ СТУПЕНИ В НРАВСТВЕННО-ЭСТЕТИЧЕСКОМ ВОСПИТАНИИ ДЕТЕЙ ДОШКОЛЬНОГО ВОЗРАСТА
}

\section{SOCIOPEDAGOGICAL MODEL OF INTERACTION BETWEEN LIBRARY- TYPE INSTITUTIONS AND PRESCHOOL EDUCATIONAL INSTITUTIONS IN THE MORAL AND AESTHETIC EDUCATION OF PRESCHOOL CHILDREN}

V. Golovachev

Summary: The article analyzes the practice of interaction between state cultural institutions (children's public libraries) and state educational institutions (preschool level) in the moral and aesthetic education of preschool children. The author's model of optimal interdepartmental interaction is presented, specific and General forms and pedagogical principles of institutions of different departmental subordination are specified. As practical examples, confirming the positive indicators of the model implementation in the practice of institutions and the theoretical arguments of the author, the indicators of the implementation of developed and implemented educational projects for preschoolers are given.

Keywords: model, interaction, library-type institution, library, preschool level institution, preschool children, moral and aesthetic education.
3 начение дошкольного возраста в теории и практике современной образовательной парадигмы заметно возрастает, период дошкольного детства становится все более активной фазой формирование основ нравственного и эстетического становления личности. Кризисные явления института семьи налагают все большую ответственность за нравственно-эстетическое становление ребенка дошкольника на государственные институции - учреждения сферы образования и культуры. Реформы отечественного образования, значительно затронули в том числе и работу с дошкольным возрастом, период обучения в дошкольном образовательном учреждении стал первой ступенью единой системы непрерывного образования.

Проблематику раннего нравственно-эстетического развития личности ребенка исследуют в своих трудах та-

\author{
Головачев Владимир Сергеевич \\ Аспирант, Московский Государственный Областной \\ Университет \\ vladgolovachev@yandex.ru
}

Аннотация: В статье приводится анализ практики взаимодействия государственных учреждений культуры (детских публичных библиотек) и государственных учреждений образования (дошкольной ступени) в нравственно-эстетическом воспитании детей дошкольного возраста. Представляется авторская модель оптимального межведомственного взаимодействия, уточняются специфические и общие формы и педагогические принципы работы учреждений разного ведомственного подчинения. В качестве практических примеров, подтверждающих положительные показатели внедрения модели в практику работы учреждений и теоретические доводы автора, приведены показатели реализации разработанных и внедренных образовательно-просветительских проектов для дошкольников.

Ключевые слова: модель, взаимодействие, учреждение библиотечного типа, библиотека, учреждение дошкольной ступени, дошкольники, нравственноэстетическое воспитание.

кие отечественные ученые и специалисты-практики, как Н.А. Ветлугина [1], Н.Е. и А.Н. Веракса [4], Н.А. Горлова [5], Т.С. Комарова [12], Г.П. Новикова [14] и др.

Значительные изменения в последние десятилетия произошли и в работе с детьми-дошкольниками на базе учреждений культуры. Специализированные программы раннего эстетического развития и приобщения к искусству появились в театрах, музеях, домах культуры [7, с.147-148]. Среди указанных государственных учреждений, особо значимые процессы обновления в работе с дошкольной аудиторией произошли в учреждениях библиотечного типа. Реформа отечественной системы публичных библиотек 1990-х-2000-х гг. в корне изменила целевое назначение учреждений, сместив акцент с таких традиционных библиотечных функций, как книгохранение и книговыдача в сторону расширения социокультур- 
ного пространства и интерактивной работы с читательской аудитории. При этом, нижние возрастные границы читателей также изменились. Ребенок дошкольник стал полноправным пользователем достаточно широкого спектра услуг библиотеки: пользование специализированным фондом для дошкольников, выделенными и специально оборудованными помещениями для читателей-дошкольников, участие в массовых мероприятиях 9библиотечных праздниках, проектах, выставках и др.), получение внестационарных услуг (передвижные книжные выставки, мобильные библиотечные пункты в открытых городских пространствах и др.).

Вопросы эффективизации нравственно-эстетического воспитания дошкольников на базе детских публичных библиотек поднимали в своих исследованиях: И.В. Балкова и Н.Н. Мисина [2], О.В. Дыбина [8], Г.Е. Жукова [10].

Значительным изменениям подверглась и законодательная база, регламентирующая работу учреждений культуры и образования с дошкольной аудиторией. Общие и специфические законодательные акты представлены в таблице 1.

Таблица 1

Законодательная база учреждений образования (дошкольной ступени) и культуры (детских публичных библиотек) в контексте работы с дошкольной аудиторией

\begin{tabular}{|l|l|}
\hline \multicolumn{2}{|c|}{ Общие законодательные акты для учреждений } \\
образования и культуры
\end{tabular}

Приведенный перечень документов показывает, что на современном этапе, при достаточной законодательной разработанности подходов к работе с дошкольной аудиторией внутри системы образования и культуры, существует определенный пробел в законодательной базе по межсистемному взаимодействию в данной сфере.

Стоит отметить, определенные пробелы и в научно-теоретической проработке вопроса: на фоне значительной разработанности в трудах отечественных ученых-теоретиков и педагогов практиков подходов к нравственно-эстетическому воспитанию дошкольников на базу учреждений образования, подобные подходы для учреждений библиотечного типа не получили достаточного научно-методического сопровождения.

Проблематика объединения межведомственного потенциала образования и культуры поднимаются в отдельных трудах таких современных отечественных исследователей, как: Е.И. Артамонова [1], М.Б. Зацепина [11], И.Н. Куланина [13, с.28-29], Г.Н. Петров [15], А.Л. Третьяков [16, с.390] и др.

Одним из важнейших аспектов теоретических и практических исследований педагогических подходов к нравственно-эстетическому воспитанию дошкольников в новых образовательных реалиях становится изучение возможностей коллаборации учреждений разной ведомственной принадлежности и выдвижение гипотезы об эффиктивизации нравственно-эстетического воспитания дошкольников при взаимодействии учреждений образования и культуры.

Учреждения разного ведомственного подчинения, работая с одной дошкольной аудиторией, не всегда в достаточной мере взаимодействуют, не интегрируют учебные планы и программы, не инициируют совместные проекты и мероприятия для дошкольников. Результатом подобной разобщенности в подходах к нравственноэстетическому воспитанию дошкольников становится информационная и эмоциональная перегрузка ребенка в следствии тематической дублируемости мероприятий, раздражение, вызываемое излишним количеством схожих творческих заданий и мероприятий.

Обозначенная выше проблема стимулирует целый спектр сопутствующих негативных факторов в работе с дошкольной аудиторией на базе учреждений образования и культуры.

Перечень выделенных автором негативных факторов (специфических и общих для сферы образования и культуры), вызванных межведомственной разобщенностью и снижающих качественный уровень нравственноэстетического воспитания, сформированный на основе анкетирования сотрудников учреждений образования 
и культуры, занимающихся с дошкольной аудиторией представлен в таблице 2.

Таблица 2.

Негативные факторы (специфические и общие)

в работе с дошкольной аудиторией на базе

учреждений образования и культуры, вызванные межведомственной разобщенностью

(по результатам обработки 186 анкет)

\begin{tabular}{|c|c|}
\hline $\begin{array}{l}\text { Учреждения образования } \\
\text { (дошкольной ступени) }\end{array}$ & $\begin{array}{l}\text { Учреждения культуры } \\
\text { (детские публичные библиотеки) }\end{array}$ \\
\hline $\begin{array}{l}\text {-недостаточная осведомлен- } \\
\text { ность о новых литературных } \\
\text { произведениях и изданиях для } \\
\text { дошкольной аудитории; } \\
\text { - недостаток основного и до- } \\
\text { сугового времени дошкольной } \\
\text { аудитории в пространстве } \\
\text { организации для приобщения к } \\
\text { книге и чтению; } \\
\text { - отсутствие или недостаток со- } \\
\text { временных технических средств } \\
\text { для демонстрации современного } \\
\text { информационно-образователь- } \\
\text { ного и справочно-воспитатель- } \\
\text { ного контента; } \\
\text { - нехватка времени в штатном } \\
\text { расписании основного персонала } \\
\text { для занятий с дошкольной ауди- } \\
\text { торией проектной и исследова- } \\
\text { тельской деятельностью. }\end{array}$ & $\begin{array}{l}\text { - недостаточный количественный } \\
\text { охват библиотечных проектов и ме- } \\
\text { роприятий дошкольной аудитории; } \\
\text { - недостаток навыков психолого-пе- } \\
\text { дагогической работы с дошкольной } \\
\text { аудиторией у сотрудников библио- } \\
\text { теки; } \\
\text { - нехватка свободного пространства } \\
\text { для полноценных игровых занятий с } \\
\text { дошкольниками; } \\
\text { - отсутствие или недостаток необхо- } \\
\text { димого инвентаря для творческой и } \\
\text { проектной работы с дошкольниками; } \\
\text { - недостаток времени в штатном } \\
\text { расписании библиотекарей для } \\
\text { полноценных для занятий с до- } \\
\text { школьной аудиторией творческой } \\
\text { деятельностью; } \\
\text { - ограниченность материально- } \\
\text { технических ресурсов и площадей } \\
\text { библиотеки для полноценной подго- } \\
\text { товки детей к творческим проектам } \\
\text { и конкурсам. }\end{array}$ \\
\hline
\end{tabular}

\section{0бщие, характерные для учреждений образования и культуры}

- недостаточная взаимная информированность о методическом, педагогическом, информационном, кадровом и материально-техническом потенциале;

- отсутствие типовых документов, регламентирующих межведомственное сотрудничество (соглашений, договоров о сотрудничестве, планов совместной работы и др.);

- недостаточность стимулирующих сотрудничество внешних (поощрение органов законодательной и исполнительной власти, местного самоуправления) и внутренних факторов (поощрение сотрудников, ведущих внестационарную работу, расширяющих социо-культурные связи учреждения);

- недостаток совместных профессиональных мероприятий по обмену опытом (межведомственных семинаров, совещаний, круглых столов, научно-практических конференций).

Приведенные выше негативные факторы, отмеченные самими сотрудниками учреждений и взаимная заинтересованности в объединении творческого, профессионального, материально-технического и кадрового потенциала подтверждают гипотезу об эффиктивизации нравственно-эстетического воспитания дошкольников при взаимодействии учреждений образования и культуры.

На основе приведенных факторов, можно сформулировать основные цели предлагаемой межведомственной коллаборации учреждений:

- взаимное обогащение опыта эффективной работы с дошкольниками (педагогического, методического);

- эффективное формирование навыков эстетического восприятия окружающего мира, а также нравственности, методами образования и культуры;

- раннее формирование морально-волевых, нравственных и эстетических качеств личности ребенка-дошкольника.

Опытно-экспериментальная работа на базе учреждений образования и культуры, среди которых: детская библиотека № 207 имени В.В Бианки ГБУК г. МоскВы «ЦБС ЗАО», библиотека № 212 им. Т.Г. Шевченко ГБУК г. Москвы «ЦБС ЗАО», дошкольные отделения ГБОУ «Школа № 2101», ГБОУ «Школа № 1359 им. авиаконструктора М.Л. Миля» позволила сформировать основные взаимные потребности учреждений и выйти на построение социопедагогической модели межведомственного взаимодействия, представленной на рисунке 1.

В центре представленной модели - ребенок дошкольного возраста, окруженный вниманием членов семьи. Учреждения образования и культуры представлены, как две равнонаправленные силы нравственно-эстетического воздействия. Проводниками учреждений и непосредственными наставниками ребенка-дошкольника на пути к становлению нравственных и эстетических качеств становятся библиотекарь и педагог ДОО, которые воздействуют на формирование указанных качеств характерными для системы образования и культуры формами работы. Для дошкольного образовательного учреждения это: игры-соревнования, творческо-изобразительная, музыкальная и театральная деятельность, экскурсии, наблюдения за явлениями природы и прогулки. Для учреждений библиотечного типа характерны такие формы стационарной работы, как организация книжно-иллюстративных выставок, библиографические игры, иллюстрирование литературных произведений, библиотечные викторины, книжные праздники, беседы и громкие чтения.

При формировании единого образовательного пространства, которое может быть закреплено подписанием соглашения/договора о сотрудничестве, утверждением совместного календарно-тематического годового плана, появляются новые формы совместной работы, 


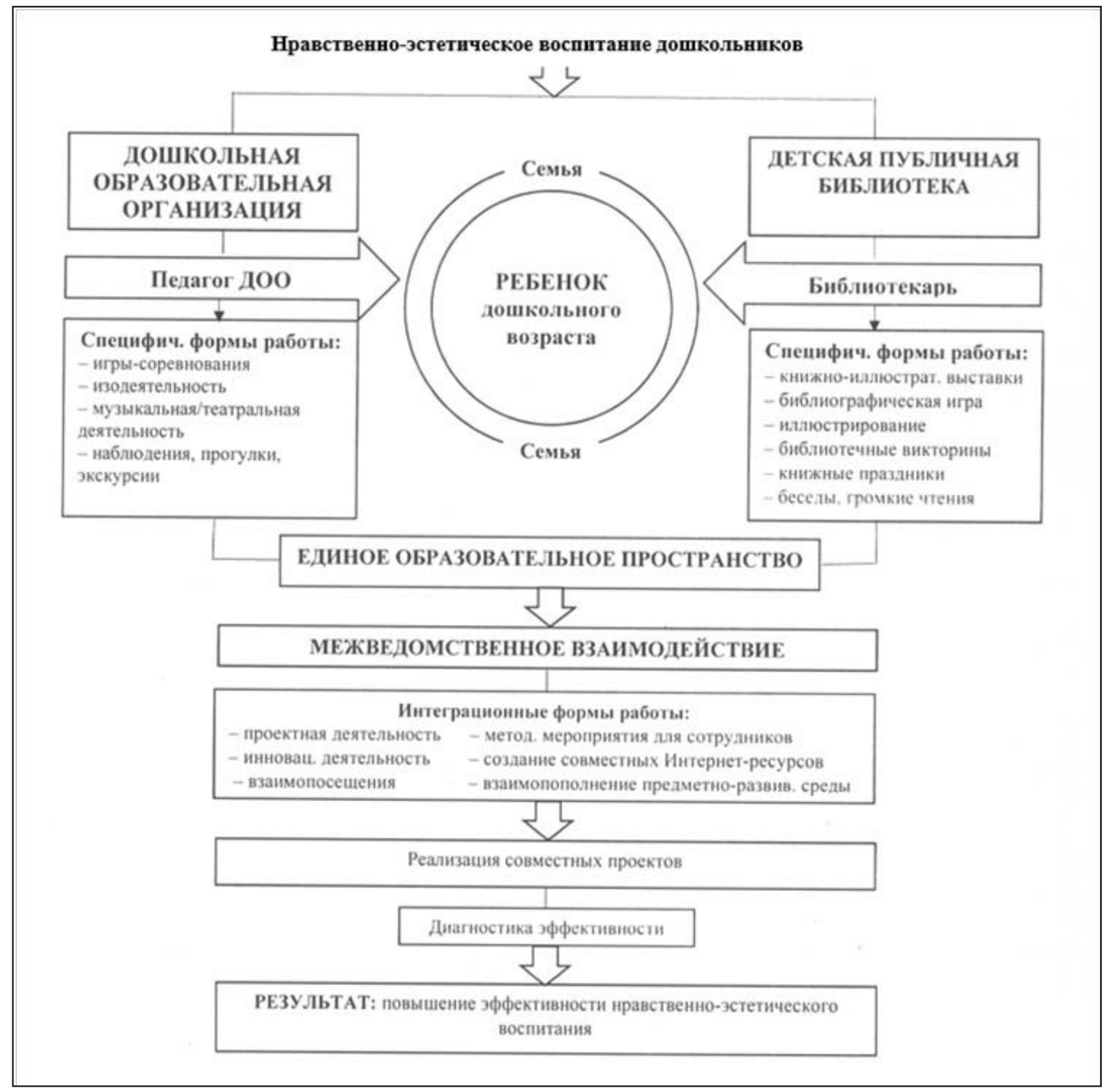

Рис.1. Социопедагогическая модель взаимодействия учреждений библиотечного типа и образовательных учреждений дошкольной ступени в нравственно-эстетическом воспитании дошкольников

среди которых можно выделить: проектную и инновационную деятельность дошкольников, взаимопосещения детей и сотрудников, совместные методические мероприятия, создание совместных интернет-ресурсов, взаимопополнение предметно-развивающей среды $[6$, с. 144-145]. Подобное межведомственное взаимодействие в пространстве единого образовательного пространства создает предпосылки для осуществление системной совместной проектной деятельности и более интенсивной и качественной работой с дошкольной аудиторией, повышающей эффективность нравственно-эстетического воспитания.
Приведенные факты теоретического анализа и практического исследования доказывают эффективность внедрения в широкую практику работы учреждений образования и культуры разработанной Социопедагогической модели межведомственного взаимодействия в нравственно-эстетическом воспитании дошкольников. Подобная модель может быть использована и в схожих системах «ДОО-театр» и «ДОО-музей» в целях интенсификации и эффективизации совместной работы по нравственно-эстетическому воспитанию детей дошкольного возраста, как одной из важнейших задач государства. 


\section{ЛИТЕРАТУРА}

1. Артамонова Е.И. Педагог в поиске инновационной деятельности// Профессиональная педагогика: сущность, содержание, перспективы развития. Материалы Международной научно-практической конференции, посвященной 130-летию со дня рождения А.С. Макаренко. Под редакцией Е.И. Артамоновой. 2019. С. 3-13.

2. Балкова И.В., Мисина Н.Н. Библиотеки и продвижение чтения: технологии XXI века// Румянцевские чтения - 2016: материалы Международной научной конференции.- М.: Пашков дом, 2016. - Ч. 1. - С. 56 -60.

3. Ветлугина Н.А., Кенеман А.В. Теория и методика музыкального воспитания в детском саду : учеб. пособие для студентов пед. ин-тов.-М. : Просвещение, 1983. -286 c.

4. Веракса Н.Е., Веракса А.Н. Проектная деятельность дошкольников: пособие для педагогов дошкольных учреждений. - М.: МОЗАИКА-СИНТЕЗ, 2010. 112 c.

5. Горлова Н.А. Современные дети и педагогические стратегии их развития // Современные тенденции развития начального и эстетического образования. Сборник статей Международной научно-практической конференции, посвященной 60-летию факультета начального и музыкального образования. 2019. С. 3-5.

6. Головачев В.С. Возможности межрегионального проектного взаимодействия учреждений образования и культуры в нравственно-эстетическом воспитании дошкольников /В.С. Головачев //Вестник Чувашского государственного педагогического университета им. И.Я. Яковлева. - 2019. - № 5 (105). - С. 143-151.

7. Головачев В.С. Реализация межрегиональных проектов этнокультурной направленности в условиях межведомственного взаимодействия // Этническая культура в современном мире. Материалы VI Международной научно-практической конференции, посвященной 100-летию образования Чувашской автономной области. Редколлегия: Л.П. Кураков [и др.]. 2020.С. 147-153

8. Дыбина О.В. Творчество - как сущностная характеристика человеческого бытия. - Москва: Педагогическое общество России, 2001. - 88 с.

9. Жукова Г.Е. Инновационный подход к организации праздников и досугов для детей дошкольного возраста // материалы 3-ей научно-практической конференции «Инновации в образовании. Современная психология в обучении. - 2014. - ( 57-62.

10. Жукова Г.Е., Головачев В.С. Возможности культурно-досуговой деятельности в развитии творческих способностей дошкольников в условиях взаимодействия учреждений образования и культуры // Вестник Чувашского государственного педагогического университета им. И.Я. Яковлева. - Чебоксары. -2019. - №1(101). - C.105-113.

11. Зацепина М.Б. Виды и формы культурно-досуговой деятельности дошкольников //Детский сад от А до Я. - 2005. - № 6. - С.4-23.

12. Комарова Т.С. Дети в мире творчества: Книга для педагогов дошкольных учреждений. -М.: Мнемозина, 1995. - 160с.

13. Куланина И.Н. Искусство как форма общения в дошкольном возрасте // Вестник МГГУ им. М.А. Шолохова. - М. - № 2.2016. - С.25-35.

14. Новикова Г.П. Преемственность и непрерывность образовательного процесса в образовательных комплексах на современном этапе // Инновационная деятельность в образовании: материалы XI Международной научно-практической конференции. / под общей редакцией Г.П. Новиковой.- ЯрославльМосква: Канцлер, 2017. - Ч. ІІ. - С.224-244.

15. Петров Г.Н. Кластерный подход к развитию образования в сфере культуры //Вестник Чувашского государственного педагогического университета им. И.Я. Яковлева. 2018. № 3 (99). С. 276-282.

16. Третьяков А.Л. Информационная компетентность как образовательный феномен /А.Л. Третьяков // Язык и актуальные проблемы образования: матер. Междунар. науч.-практ. конф. - Москва, 2018 - С. 389-392.

(с) Головачев Владимир Сергеевич (vladgolovachev@yandex.ru).

Журнал «Современная наука: актуальные проблемы теории и практики» 